\title{
Association of Alopecia Areata with Vitamin D and Calcium Levels: A Systematic Review and Meta- analysis
}

Yi Liu · Jing Li · Guirong Liang • Chaojiang Cheng • Yue Li •

Xinfeng $\mathrm{Wu}$

Received: May 10, 2020 / Published online: August 9, 2020

(C) The Author(s) 2020

\section{ABSTRACT}

Introduction: To investigate the associations of alopecia areata (AA) with serum vitamin D and calcium levels.

Methods: A systematic review of all relevant articles published up to February 2020 in PubMed, Embase, and Cochrane Library databases was conducted. Primary endpoints were serum 25-hydroxyvitamin D [25(OH)D] levels and vitamin $\mathrm{D}$ deficiency, and the secondary endpoint was serum calcium level. Odds ratio (OR) and standardized mean difference (SMD) with 95\% CI across studies were analyzed.

Results: Data on 1585 patients with AA and 1114 controls from 16 case-control studies and three cross-sectional studies were included in

Digital Features To view digital features for this article go to https://doi.org/10.6084/m9.figshare.12706562.

Electronic supplementary material The online version of this article (https://doi.org/10.1007/s13555020-00433-4) contains supplementary material, which is available to authorized users.

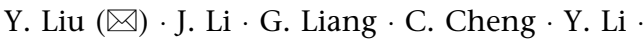

$\mathrm{X} . \mathrm{Wu}(\triangle)$

Department of Plastic and Reconstructive Surgery, Institute of Dermatology, Chinese Academy of

Medical Sciences, Peking Union Medical College,

Nanjing, China

e-mail: liuyi0513@aliyun.com

$\mathrm{X} . \mathrm{Wu}$

e-mail: wuxinfengdr@163.com this meta-analysis. A pooled meta-analysis was conducted using the random-effects model because of inter-study heterogeneity (vitamin D level, $I^{2}=87.90 \%$; vitamin D deficiency, $I^{2}=81.10 \%$; serum calcium level, $I^{2}=83.80 \%$ ). A combined analysis revealed that patients with AA had significantly lower mean serum 25(OH)D level compared with control (WMD $-9.08,95 \%$ CI $-11.65,-6.50, p<0.001)$, and were more likely to have vitamin $\mathrm{D}$ deficiency (OR 4.14, 95\% CI 2.34, 7.35, $p<0.001$ ). However, the pooled analysis revealed that patients with AA did not have significantly lower serum calcium levels compared with control (WMD $-0.17,95 \%$ CI $-0.40,0.06, p=0.143)$. Subgroup analysis suggested that matched control, mean age, and country might contribute to the heterogeneity of serum vitamin D level, while study design, matched control, and country might contribute to the heterogeneity of vitamin D deficiency.

Conclusion: Deficiency of serum 25(OH)D level, rather than calcium level, was present in patients with AA. Screening for vitamin D deficiency and vitamin $\mathrm{D}$ supplementation may be beneficial in the treatment of patients with AA.

Keywords: Alopecia areata; Areata; Calcium; Vitamin D; 1,25-Dihydroxyvitamin D; 25Hydroxyvitamin D 


\section{Key Summary Points}

Why carry out this study?

Alopecia areata (AA) is a form of nonscarring hair loss characterized by an autoimmune reaction to hair follicles with disordered, shortened hair cycle

Vitamin D deficiency was considered as a risk factor for the development of AA

The relationship between vitamin D deficiency and AA in patients was reported in two previous meta-analyses but not comprehensively evaluated because five subsequent studies were not considered

\section{What was learned from the study?}

Deficiency of serum 25(OH)D level, rather than calcium level, was present in patients with AA. Screening for vitamin D deficiency and vitamin D supplementation may be beneficial in treatment of patients with AA

\section{INTRODUCTION}

Alopecia areata (AA) is a form of non-scarring hair loss characterized by an autoimmune reaction to hair follicles with disordered, shortened hair cycle [1]. The prevalence of AA is $0.1-0.2 \%$, with a calculated lifetime risk of $2 \%$ [2]. The age- and sex-adjusted incidence of AA is 20.9 per 100,000 person-years [3]. About $51 \%$ of patients with AA are female, and the median age at diagnosis is 33 years, affecting both children and adults, and hair of all colors [3]. Earlier age of onset and male gender appear to have more severe involvement [4]. The hallmark of $\mathrm{AA}$ is $\mathrm{T}$ cell $\left(\mathrm{CD}^{+}\right.$and $\left.\mathrm{CD}^{+}\right)$infiltrates and cytokine production, specifically targeting anaphase hair follicles $[5,6]$. Autoantibodies targeting hair follicles, especially against keratin 16 and trichohyalin, are increased in peripheral blood of patients with AA [7].

Although the etiology is different between chemotherapy-induced alopecia (cytotoxic agents killing the rapidly renewing cells in the hair follicles) and AA (autoimmunity), vitamin D deficiency might be considered a risk factor for the development of AA since vitamin D protects hair follicles from chemotherapy-induced alopecia $[8,9]$. Keratinocytes possess the enzymatic machinery to synthesize active vitamin $D$, i.e., 1,25-dihydroxyvitamin $\mathrm{D}_{3}$ [serum $1,25(\mathrm{OH}) \mathrm{D} 3$ ], and express the vitamin D receptor (VDR), which is necessary for the maintenance of the normal hair cycle [10]. Besides, 1,25(OH)D3 acts as an immunomodulator of innate and adaptive immune functions targeting various immune cells such as T lymphocytes, B lymphocytes, monocytes, macrophages, and dendritic cells [11]. The association between vitamin $D$ and several autoimmune-mediated diseases has been reported, including vitiligo, systemic lupus erythematosus, type I diabetes mellitus, rheumatoid arthritis, psoriasis, multiple sclerosis, and inflammatory bowel disease [12]. Although associations are not causative factors, that might imply that vitamin D deficiency is an environmental trigger for the induction of abnormal autoimmunity [13]. Therefore, 1,25(OH)D3 modulates both innate and adaptive immune responses by targeting various immune cells such as T lymphocytes, B lymphocytes, monocytes, macrophages, and dendritic cells, among others [11]. In addition, vitamin D synthesis decreases with age [14-16]. Vitamin D deficiency is common in both men and women, and can affect pregnancy outcomes in women and increase the risk of osteoporosis, especially in menopausal women [14-17]. Although the relationship between vitamin D deficiency and AA in patients was reported in two previous meta-analyses $[18,19]$, this relationship has not been comprehensively evaluated since five subsequent studies were not considered [20-24].

Vitamin D is also a secosteroid hormone, primarily synthesized in epidermal keratinocytes or acquired from the diet, and plays an important role in calcium homeostasis and bone health $[25,26]$. Two studies revealed no difference in serum calcium levels between patients with AA and controls despite a statistically significant difference in vitamin D levels [20, 27]. The 
presence of 25-hydroxyvitamin D [25(OH)D] deficiency in patients with AA correlated with increased parathyroid hormone (PTH) [24], suggesting a compensatory effect of increased PTH to maintain normal serum calcium in a state of vitamin D deficiency. Darwish et al. showed lower levels of calcium but comparable PTH level [22], while Yilmaz et al. showed comparable levels of both calcium and PTH in patients with AA compared to controls [20].

In this context, the study aimed to evaluate the serum 25(OH)D levels and calcium levels in patients with AA in order to identify their potential roles in the pathogenesis of AA. This article is based on previously conducted studies and does not contain any studies with human participants or animals performed by any of the authors.

\section{METHODS}

\section{Search Strategy}

This meta-analysis was performed in accordance with the Preferred Reporting Items for Systematic Reviews and Meta-Analyses (PRISMA) reporting guidelines. An electronic search of the PubMed, Embase, and Cochrane Library databases was performed up to February 18, 2020, without language restrictions. We first screened the abstracts and then chose relevant full-text articles. The reference lists of selected articles were manually searched to identify additional relevant reports.

\section{Selection Criteria}

The inclusion criteria were as follows: (1) diagnoses of AA were based on clinical findings; (2) studies centered on associations of AA with vitamin D and calcium; (3) either serum 25-hydroxyvitamin D levels or vitamin D deficiency or calcium level was available for cases and controls; (4) only the publication with the largest number of participants was included for studies involving overlapping data sets; (5) publication of sufficient information to calculate odds ratios (OR) and weighted mean difference (WMD); and (6) published in peerreviewed journals.

The exclusion criteria were as follows: (a) studies without a designated control; (b) the presence of other diseases influencing 25-hydroxyvitamin D and calcium level; (c) summaries, abstracts, case reports, and reviews; (d) studies reported in a language other than English.

\section{Data Extraction and Assessment of Risk of Bias}

Two blinded and independent researchers (Yi Liu and Jing Li) reviewed potentially relevant publications, and any disagreements were resolved by a third senior researcher (Xinfeng $\mathrm{Wu}$ ). Two investigators independently extracted the following information using a predefined data collection form: author, year of publication, patient and control group characteristics, study design, sample size, gender, country or race, the outcome of interest, etc. Disagreements were resolved by consensus between the two investigators. We attempted to contact the authors for missing primary and secondary outcomes.

The Agency for Healthcare Research and Quality (AHRQ) and Newcastle-Ottawa Scale (NOS) scales were used to independently assess the methodological quality of cross-sectional studies and case-control studies, respectively.

\section{Outcomes}

The primary outcomes were serum 25-hydroxyvitamin D levels and vitamin D deficiency, and the secondary outcome was the serum calcium level. Vitamin D deficiency was defined as serum $25(\mathrm{OH}) \mathrm{D}$ level lower than 20 or $30 \mathrm{ng} / \mathrm{dL}$ depending on the study.

\section{Statistical Analysis}

The odds ratios (ORs) of having vitamin D deficiency were estimated for each study by comparing patients with AA versus healthy controls and then pooled. The ORs were pooled using the DerSimonian and Laird method if 
heterogeneity was present; otherwise, they were pooled using a fixed-effects model. For continuous outcomes, the mean difference of serum 25-hydroxyvitamin D level and calcium level between patients with AA versus healthy controls was estimated for each study and then pooled across studies using weighted mean difference (WMD). Heterogeneity was assessed using $Q$ statistics, and the degree of heterogeneity was quantified using $I^{2}$. If heterogeneity was detected ( $p<0.10$ or $I^{2} \geq 50 \%$ ), a randomeffects model was applied; otherwise, a fixedeffects model was used. In order to check the stability of the result, a sensitivity analysis was performed by sequential deletion of each study. Rosenthal's fail-safe $N$ was utilized for sensitivity analysis. The risk of publication bias was evaluated via Egger's test, Begg's test, and funnel plots. Subgroup analysis was performed to investigate the potential additional effect of predefined factors. A two-tailed $p<0.05$ was considered significant. All statistical analyses in this meta-analysis were performed using the STATA MP 14.0 software (StataCorp, College Station, TX, USA).

\section{RESULTS}

\section{Characteristics of Included Studies}

The flowchart of the study selection process is shown in Fig. 1. There were 19 eligible publications (16 case-control studies and three crosssectional studies), involving 2699 subjects (1585 AA cases and 1114 controls) [20-24, 27-40]. The sample size of the included studies ranged from 43 to 756 , and publication date from 2012 to 2019. The included studies were from eight countries, namely Egypt, India, Israel, Italy, Nepal, Pakistan, Turkey, and the USA. Eleven studies had age- and sex-matched controls. Seventeen, thirteen, and six studies provided data on serum $25(\mathrm{OH}) \mathrm{D}$ levels, vitamin D deficiency, and serum calcium level, respectively. Detailed characteristics of the included studies are summarized in Table 1 . The integral quality of the included case-control and cross-sectional studies was rated as high (sTables 1 and 2 in the supplementary material).

\section{Heterogeneity and Publication Bias}

During pooled meta-analysis, inter-study heterogeneity $\left(I^{2}>50 \%\right)$ was found in vitamin D level $\left(I^{2}=87.90 \%, p<0.001\right.$, Fig. 2), vitamin D deficiency $\left(I^{2}=81.10 \%, p<0.001\right.$, Fig. 3), and serum calcium level $\left(I^{2}=83.80 \%\right.$, $p<0.001$, Fig. 4). Therefore, the pooled metaanalysis for these factors was conducted using the random-effects model.

No evidence of publication bias was identified in the meta-analysis of serum vitamin $\mathrm{D}$ level (Begg's test, $p=0.650 ;$ Egger's test, $p=0.756)$ and vitamin D deficiency (Begg's test, $p=0.583 ; \quad$ Egger's test, $p=0.257)$. Visual inspection of the funnel plots revealed no evidence of publication bias for serum vitamin $\mathrm{D}$ levels and vitamin D deficiency (sFigs. 2 and 4 in the supplementary material). Therefore, these data indicated that there was no publication bias in the present meta-analysis, and the results were statistically robust.

\section{Meta-analysis Results}

According to inter-study heterogeneity by $Q$ test and $I^{2}$ test, the pooled analysis was conducted using the random-effects model for vitamin D level, vitamin D deficiency, and calcium level. Among the 17 studies with serum 25(OH)D level data, the results showed that patients with AA had significantly lower mean serum 25(OH)D level compared with controls (WMD 9.08, 95\% CI - 11.66, - 6.50, $p<0.001$, Fig. 2).

Among the 13 studies with vitamin $\mathrm{D}$ deficiency data, the meta-analysis suggested that patients with AA were more likely to have vitamin D deficiency with a pooled OR of 4.14 (95\% CI 2.34, 7.35, $p<0.001$, Fig. 3). Among the six included studies with serum calcium level data, the findings revealed that patients with AA did not have a statistically lower mean serum calcium level compared with controls (WMD $-0.17,95 \%$ CI $-0.40,0.06, p=0.143$, Fig. 4).

\section{Subgroup Analysis}

For serum 25(OH)D levels, similar statistically significant findings were obtained for subgroup 


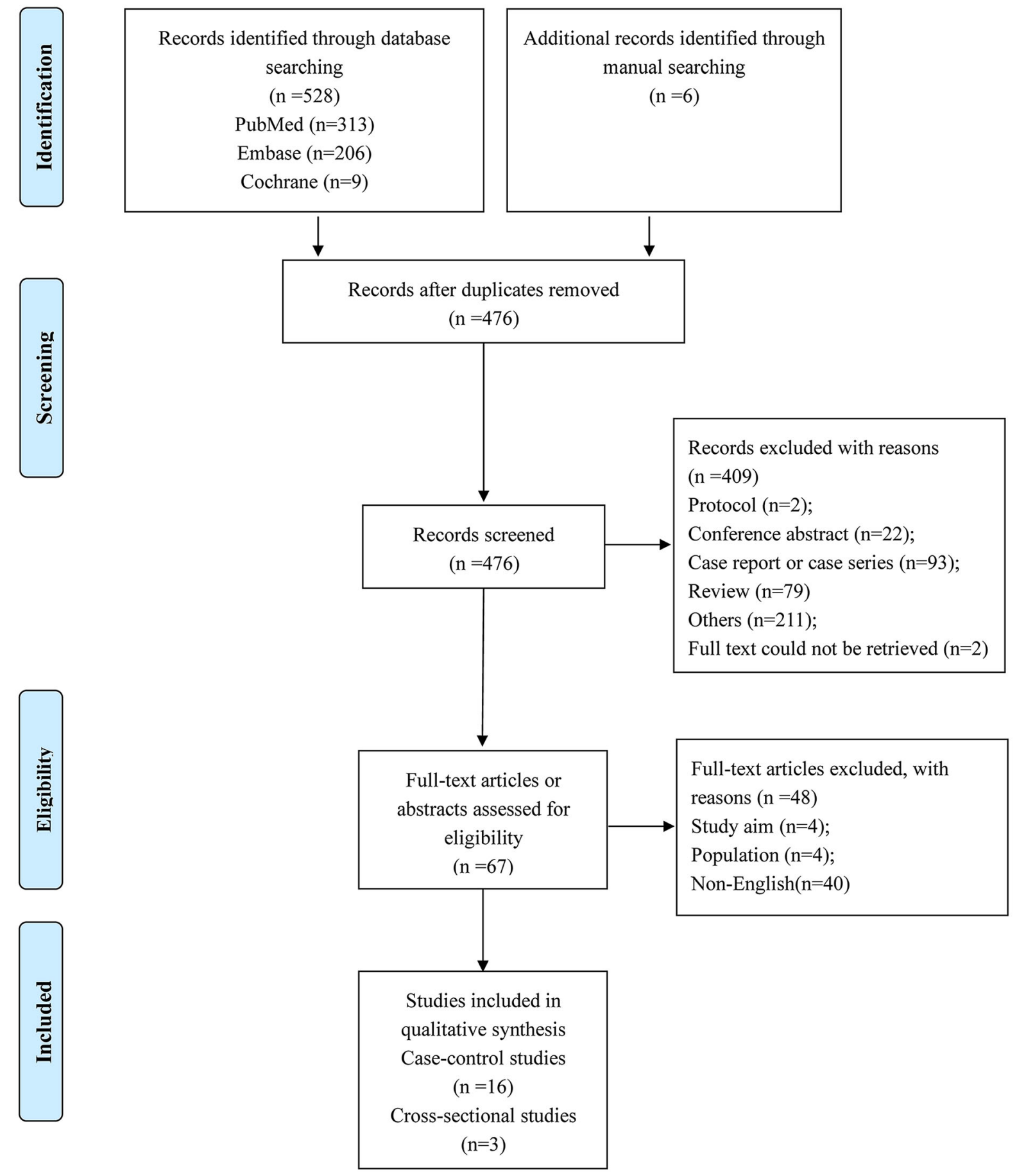

Fig. 1 Flowchart of literature search and study selection

analyses of study design (WMD of case-control - 9.05, 95\% CI - 12.46, - 5.63; WMD of crosssectional $-9.82,95 \%$ CI $-11.91,-7.72$ ), sample size (WMD of > 100: $-8.35,95 \%$ CI
$-11.19,-5.51$; WMD of $\leq 100:-9.59,95 \%$ CI $-13.44,-5.74$ ), and male ratio (WMD of $>1 / 2$ : $-7.79,95 \%$ CI - 11.47, - 4.11; WMD of $\leq 1 / 2:-12.03,95 \%$ CI $-16.93,-7.13$ ) 


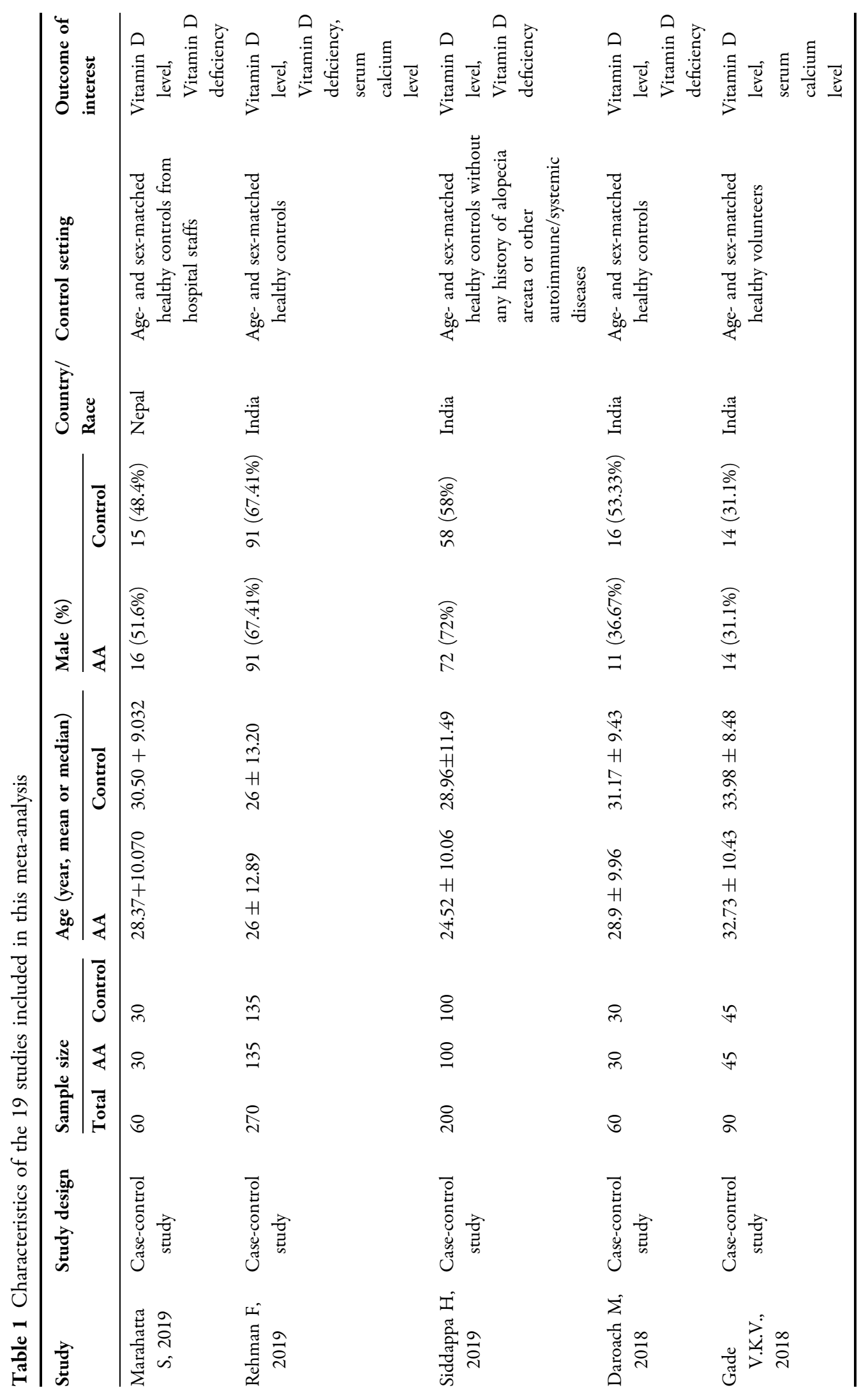




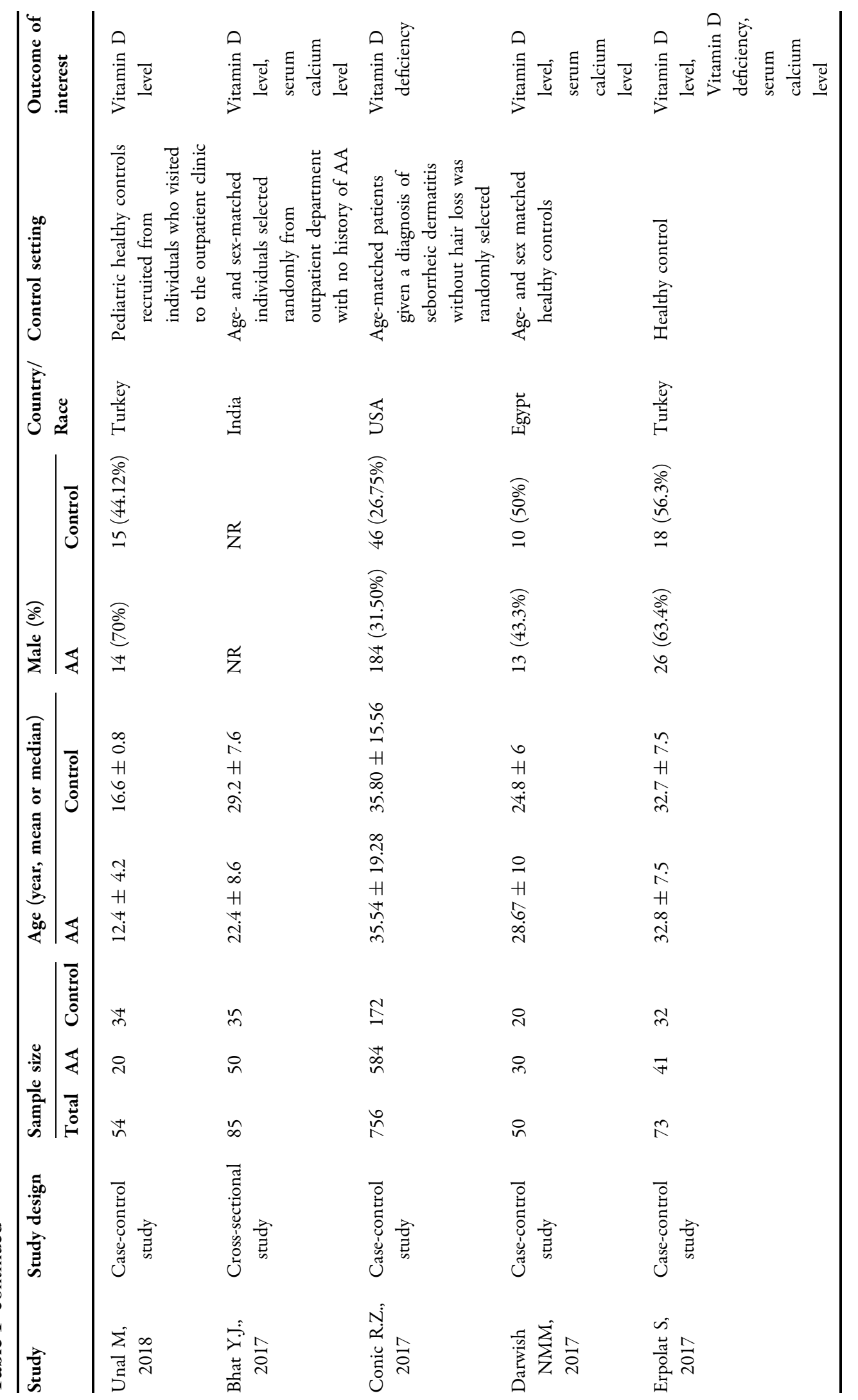




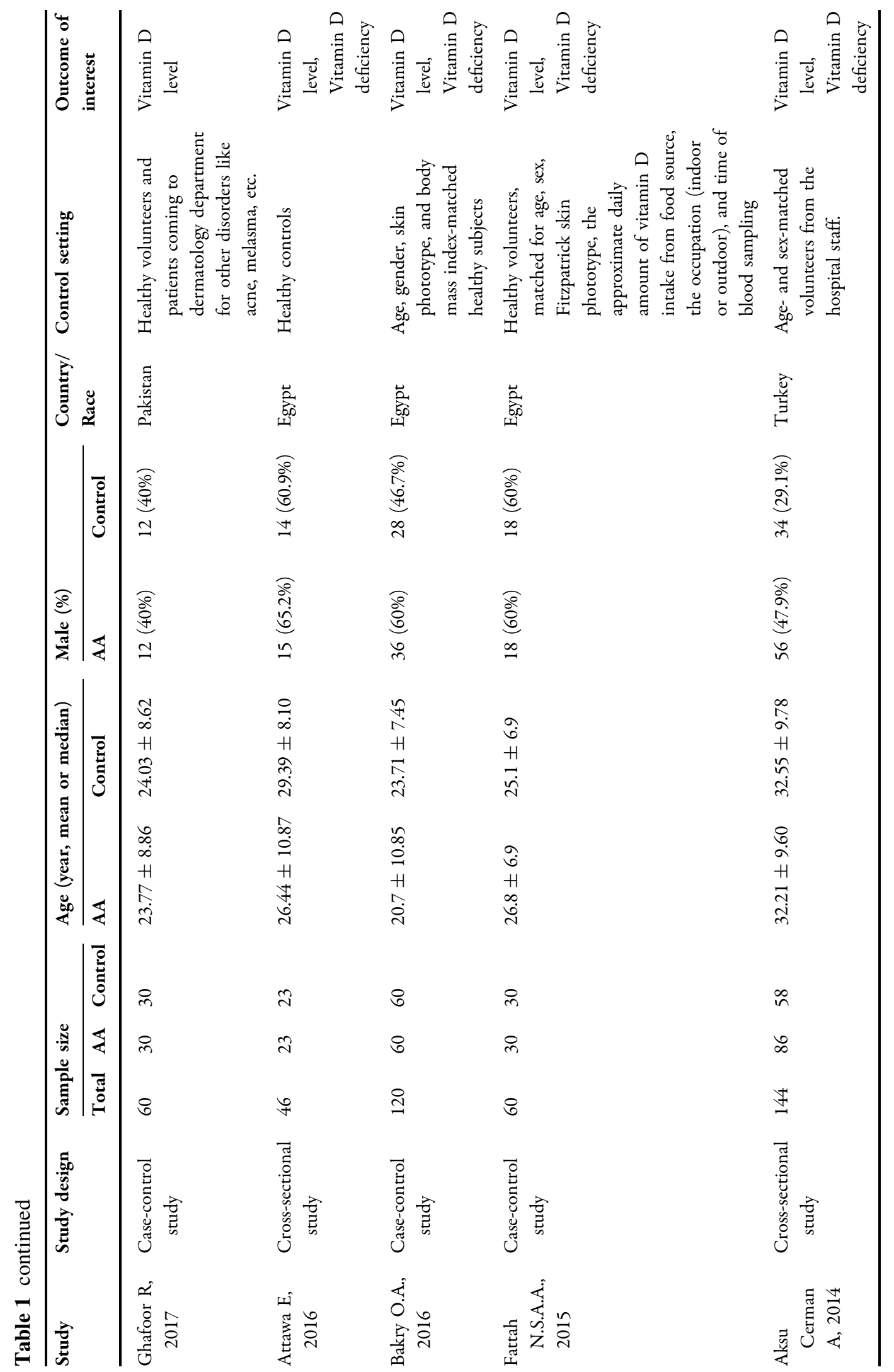




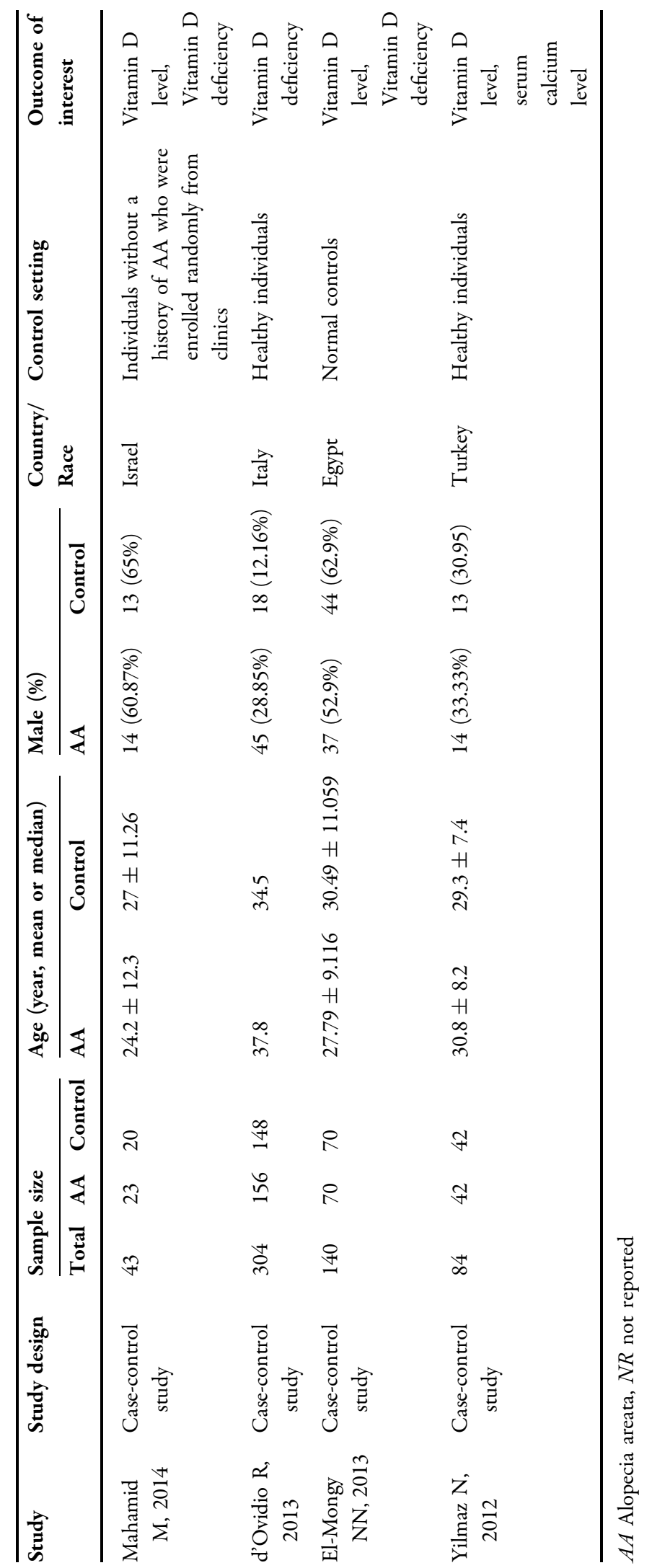




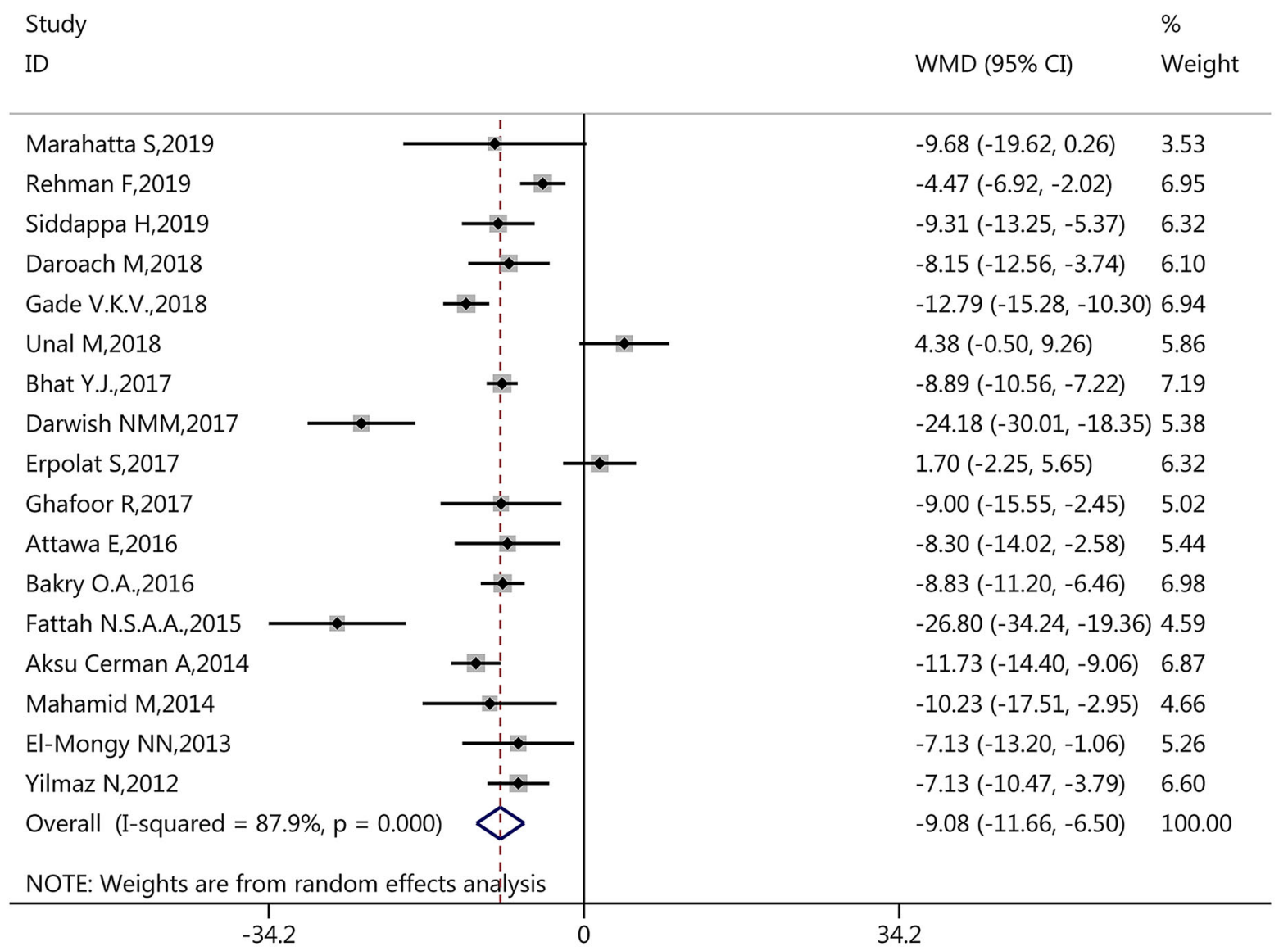

Fig. 2 Forest plot of the meta-analysis of serum vitamin D level

(Table 2). However, inconsistent results were found for matched control (WMD of matched control - 11.38, 95\% CI - 13.99, - 8.78; WMD of non-matched control $-3.18,95 \% \mathrm{CI}-8.35$, 1.99 ), mean age (WMD of $>25$ years -10.06 , $95 \%$ CI $-12.87,-7.24$; WMD of $<25$ years $-3.18,95 \%$ CI $-8.35,1.99$ ), country (WMD of Nepal $-9.68,95 \%$ CI $-19.62,0.26$, WMD of India $-8.73,95 \% \mathrm{CI}-11.59,-5.87$; WMD of Turkey $-3.37,95 \%$ CI $-10.68,3.94$; WMD of Egypt $-14.75,95 \%$ CI $-22.10,-7.39$; WMD of Pakistan - 9.00, 95\% CI - 15.55, - 2.45; WMD of Israel - 10.23, 95\% CI - 17.51, -2.95 ) (Table 2). These findings suggested that matched control, mean age, and country might contribute to a high degree of inter-study heterogeneity in serum vitamin D level.
For vitamin D deficiency, consistent statistically significant findings were identified for subgroup analyses of sample size (OR of $>100$ : $3.94,95 \%$ CI 2.06, 7.54; OR of $\leq 100: 5.36,95 \%$ CI $1.29,22.21)$, male ratio (OR of $>1 / 2: 4.51$, $95 \%$ CI $2.05,9.93$; OR of $\leq 1 / 2: 3.24,95 \%$ CI $1.37,7.63)$, and mean age (OR of $>25$ years: $3.58,95 \%$ CI 2.04, 6.28; OR of $<25$ years: 16.43 , 95\% CI 6.65, 40.61) (Table 2). However, inconsistent results were found for study design (OR of case-control 3.66, 95\% CI 2.06, 6.49; OR of cross-sectional $6.65,95 \%$ CI $0.65,68.27)$, matched control (OR of matched control 6.96, 95\% CI 3.54, 13.68; OR of non-matched control $1.52,95 \%$ CI 1.00, 2.32), and country (OR of Nepal 4.38, 95\% CI 1.32, 14.50, OR of India 2.55, 95\% CI 1.54, 4.21; OR of Turkey 2.97, 95\% 


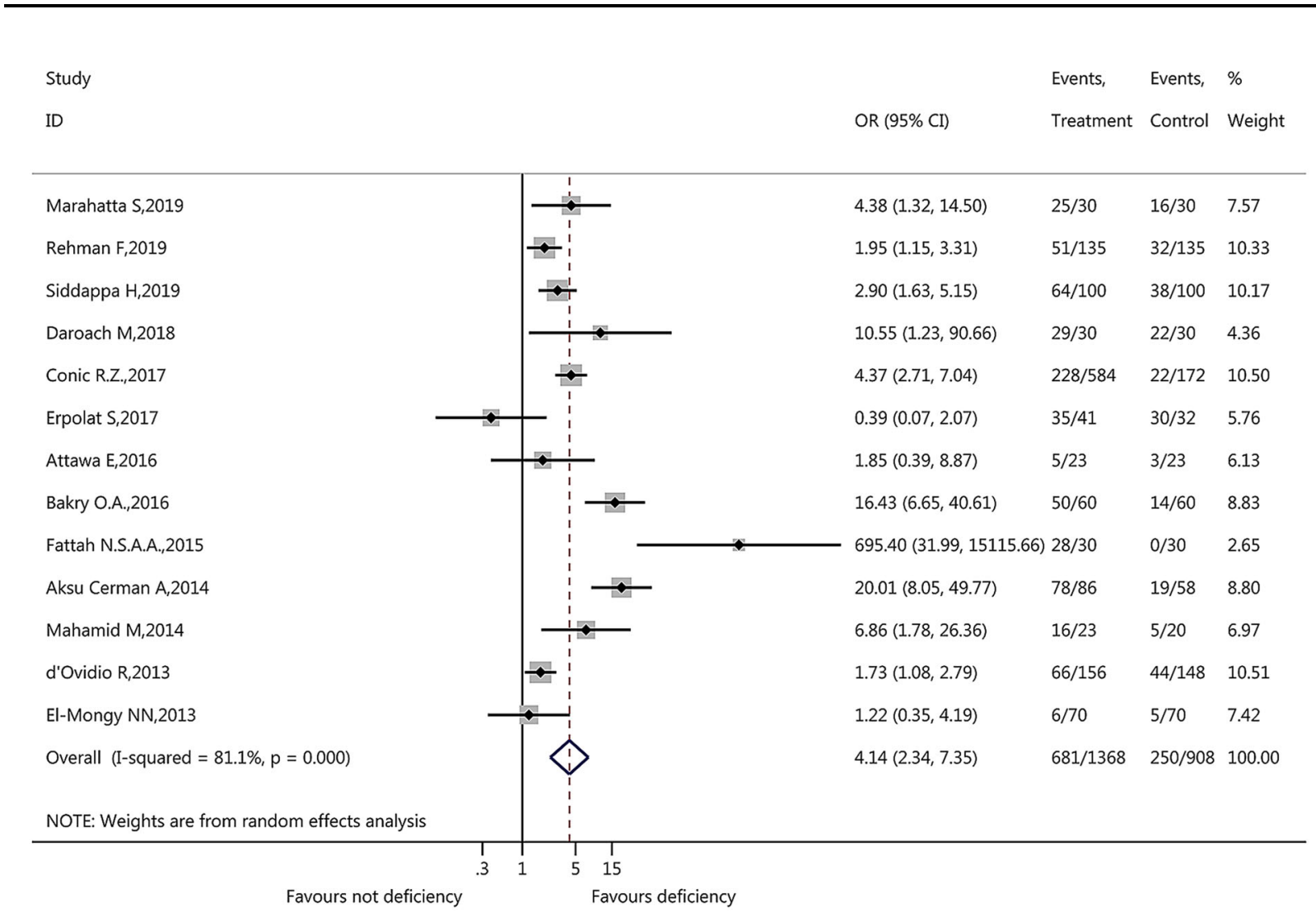

Fig. 3 Forest plot of the meta-analysis of vitamin D deficiency

CI 0.06, 147.87; OR of Egypt 8.91, 95\% CI 1.20, 66.39; OR of Israel $6.86,95 \%$ CI 1.78, 26.36; OR of Italy $1.73,95 \%$ CI 1.08, 2.79; OR of USA 4.37, 95\% CI 2.71, 7.04) (Table 2). These data suggested that study design, matched control, and country might contribute to a high degree of inter-study heterogeneity in vitamin $D$ deficiency.

\section{Sensitivity Analysis}

A sensitivity analysis was performed to check the robustness of the results. Statistically similar outcomes were obtained for meta-analysis of vitamin D level (sFig. 1 in the supplementary material) and vitamin D deficiency (sFig. 3 in the supplementary material) after sequentially excluding each case-control study, indicating the stability of the present meta-analysis.

\section{DISCUSSION}

The present systematic review and meta-analysis indicated that patients with AA had lower serum 25(OH)D3 level and higher risk of vitamin D deficiency, but not lower serum calcium level compared with controls. Thus, screening for vitamin D deficiency and supplementation of vitamin $D$ could be beneficial in the treatment of AA. In addition to regulating bone and calcium metabolism, the biologically active metabolite of vitamin $\mathrm{D}_{3}, 1,25(\mathrm{OH}) 2 \mathrm{D} 3$, can modulate nuclear vitamin $\mathrm{D}$ receptor expressed in antigen-presenting cells (APCs) and activated $T$ cells via interference with nuclear transcription factors such as NF-AT and NF- $\kappa \mathrm{B}$ or by direct interaction with vitamin $\mathrm{D}$ responsive elements in the promoter regions of cytokine genes [41]. 


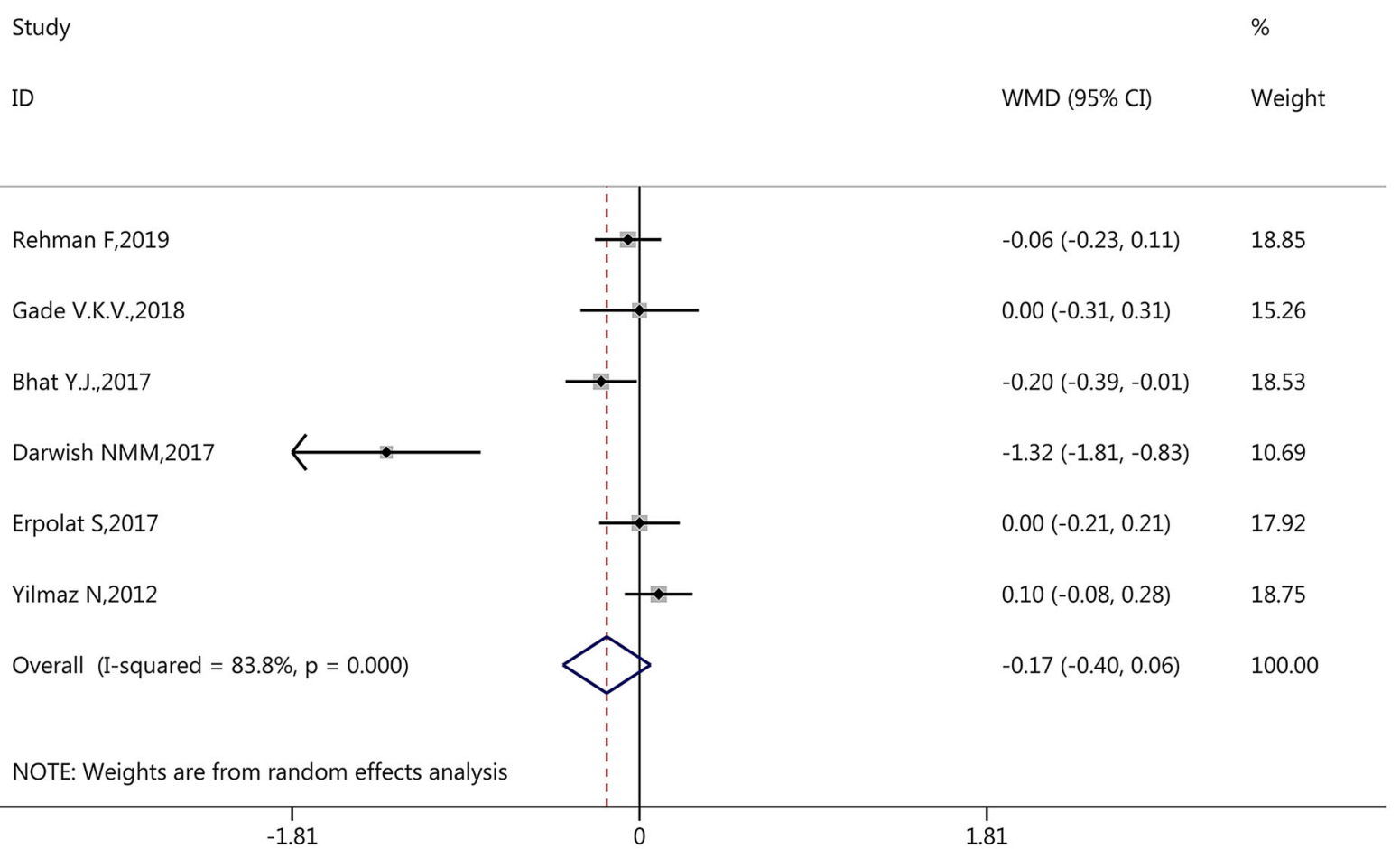

Fig. 4 Forest plot of the meta-analysis of serum calcium level

The beneficial effect of vitamin $\mathrm{D}_{3}$ is mediated through the prevention of strong Th1 cell responses via the action on APCs, while simultaneously tilting the $\mathrm{T}$ cell response towards Th2 dominance [41, 42]. The beneficial effect of vitamin D supplementation was observed in the prevention and treatment of autoimmune-mediated diseases [43-45], but no study was conducted in patients with AA. A 7-year-old patient with $\mathrm{AA}$ and reduced vitamin $\mathrm{D}$ receptor expression recovered after topical application of calcipotriol, a strong vitamin D analogue [46]. The mechanism of topical application of calcipotriol in the restoration of hair cycle dysfunction is believed to regulate the differentiation of different cells and the expression of Toll-like receptors [44]. Therefore, large prospective studies are required to confirm the role of vitamin D supplementation in the treatment of AA, especially the severe form, which is commonly associated with other autoimmune diseases [47].
This study had two strengths that likely increased the reliability and clinical value of the findings. First, compared with the previous two studies $[18,19]$, the results of the present study were more reliable as we extensively searched to include all potentially eligible studies. Second, unlike the two previous studies, our pooled analysis of six studies revealed that patients with AA did not have a statistically lower mean serum calcium level compared with controls. A plausible explanation of normal calcium level is the compensatory increase in PTH during vitamin D deficiency. Nevertheless, Darwish et al. revealed lower levels of serum $25(\mathrm{OH}) \mathrm{D}$ and calcium but comparable PTH level in patients with AA compared with controls [22]; they also showed a positive linear correlation between serum vitamin $\mathrm{D}$ and serum calcium in patients with AA. Yilmaz et al. also found no significant difference in PTH level between patients with AA and controls [20]. Thus, whether there is a compensatory effect of increased PTH and how 


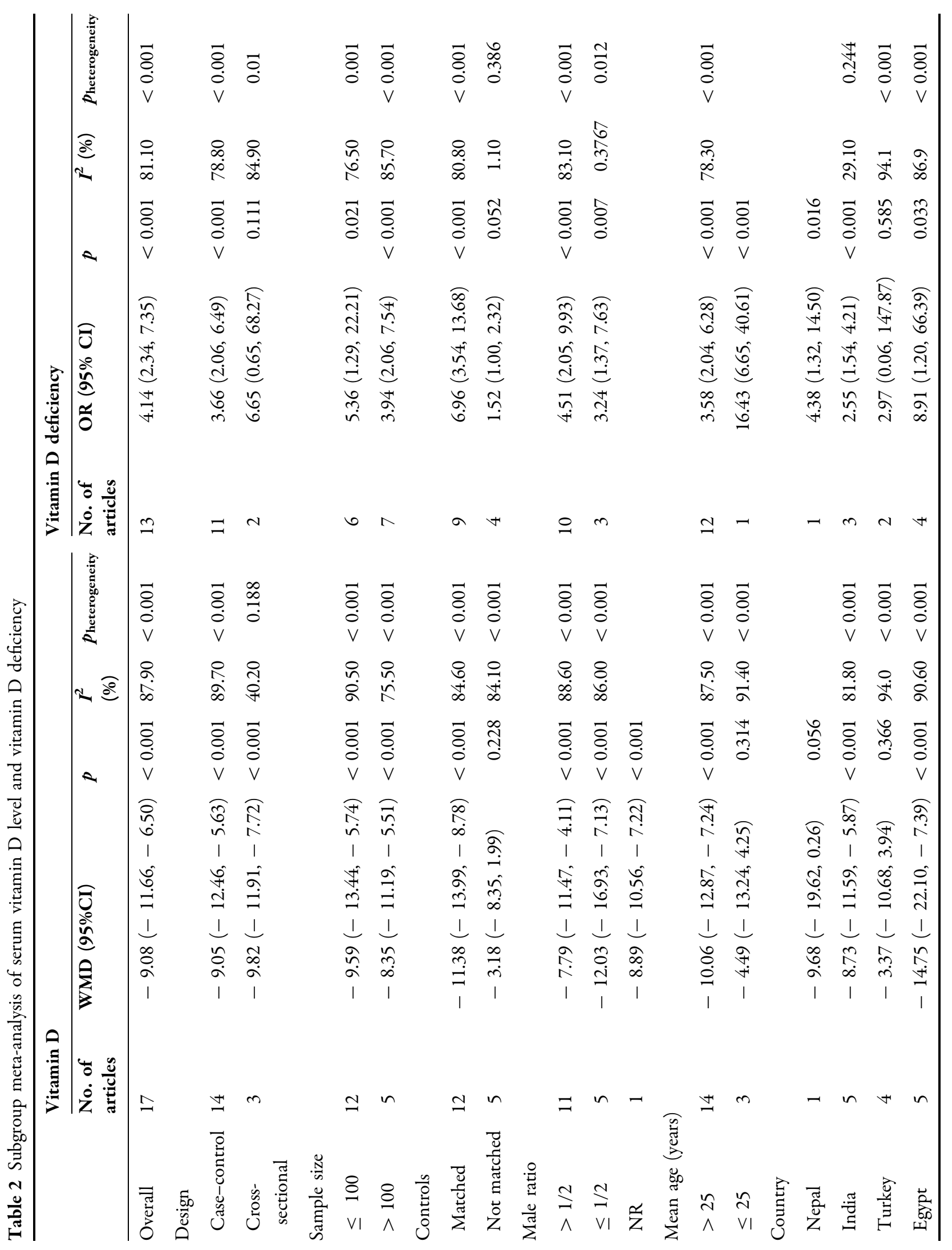




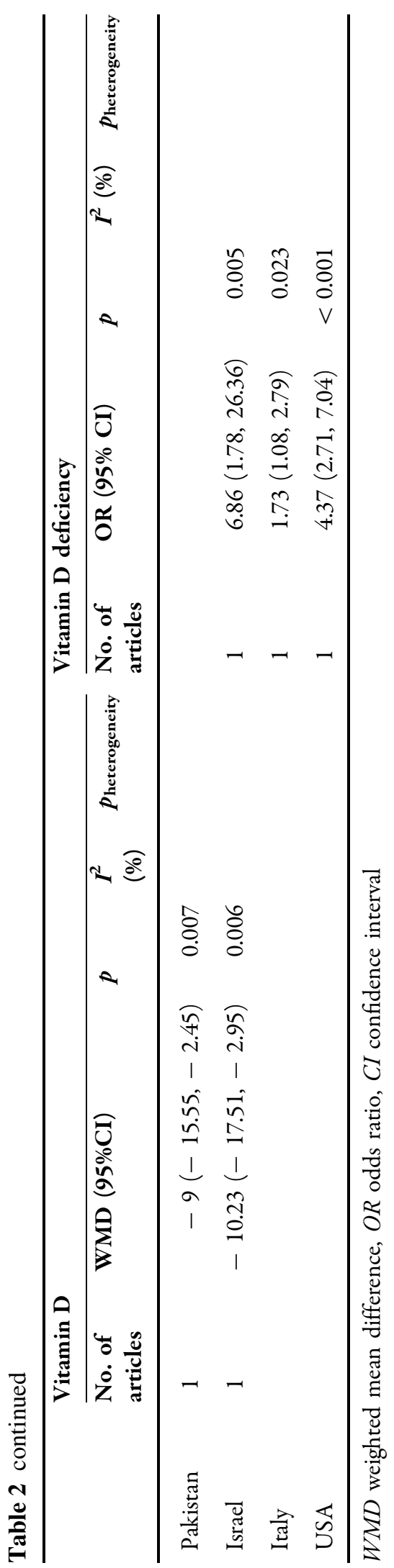

it works in patients with AA need further investigation.

This meta-analysis had several potential limitations that must be considered when interpreting the results. First, a meta-analysis is unable to resolve problems with confounding factors that could be inherent in the original studies, although major potential confounders had been adjusted for in most of the included studies. Subgroup analysis suggested that the heterogeneity of serum vitamin D level was partially explained by matched controls, mean age, and country, while heterogeneity of vitamin $\mathrm{D}$ deficiency was partly explained by study design, matched controls, and country. Therefore, a random-effects model was used for the synthesis of data in order to mitigate potential variation between patients at an individual patient data level. Second, the results of several subgroups were based on a limited number of studies, and therefore, the possibility of insufficient statistical power cannot be ruled out. For example, the only study on pediatric patients with AA reported no difference in serum 25(OH)D level between pediatric patients with AA and pediatric controls [37]. Hence, caution should be used for generalization of these findings to pediatric patients with AA. Third, serum $25(\mathrm{OH}) \mathrm{D}$ concentration might be influenced by numerous factors such as gender, age, ethnicity, comorbidity, diet, sun exposure level, the season of blood sampling, and treatments, such as phototherapy. Therefore, a Mendelian randomization study might be useful to determine the causal association between vitamin $\mathrm{D}$ and AA. Fourth, most included studies defined vitamin D deficiency as serum $25(\mathrm{OH}) \mathrm{D}$ level below $20 \mathrm{ng} / \mathrm{dL}$, but a few studies defined it as below $30 \mathrm{ng} / \mathrm{dL}$. However, subgroup analysis of different definitions of vitamin $\mathrm{D}$ deficiency was consistent with the overall analysis. Finally, only studies published in English were included, and valuable data published in other languages might have been excluded.

\section{CONCLUSIONS}

Deficient serum 25(OH)D level, rather than calcium level, was present in patients with AA. 
Screening for vitamin D deficiency and vitamin D supplementation may be beneficial in the treatment of patients with AA. As a result of the limited data, we were unable to comment on the potential additional effect of calcium monitoring.

\section{ACKNOWLEDGEMENTS}

Funding. No funding or sponsorship was received for this study or publication of this article. The Rapid Service Fee was funded by the authors.

Authorship. All named authors meet the International Committee of Medical Journal Editors (ICMJE) criteria for authorship for this article, take responsibility for the integrity of the work as a whole, and have given their approval for this version to be published.

Authorship Contributions. Yi Liu and Jing Li carried out the studies, participated in collecting data, and drafted the manuscript. Guirong Liang, Chaojiang Cheng and Yue Li performed the statistical analysis and participated in its design. Yi Liu, Jing Li and Xinfeng $\mathrm{Wu}$ participated in the acquisition, analysis, or interpretation of data and drafted the manuscript. All authors read and approved the final manuscript. Yi Liu and Jing $\mathrm{Li}$ contributed equally to this article.

Disclosures. Yi Liu, Jing Li, Guirong Liang, Chaojiang Cheng, Yue Li and Xinfeng Wu have nothing to disclose.

Compliance with Ethics Guidelines. This article is based on previously conducted studies and does not contain any studies with human participants or animals performed by any of the authors.

Data Availability. All data generated or analyzed during this study are included in this published article/as supplementary information files.
Open Access. This article is licensed under a Creative Commons Attribution-NonCommercial 4.0 International License, which permits any non-commercial use, sharing, adaptation, distribution and reproduction in any medium or format, as long as you give appropriate credit to the original author(s) and the source, provide a link to the Creative Commons licence, and indicate if changes were made. The images or other third party material in this article are included in the article's Creative Commons licence, unless indicated otherwise in a credit line to the material. If material is not included in the article's Creative Commons licence and your intended use is not permitted by statutory regulation or exceeds the permitted use, you will need to obtain permission directly from the copyright holder. To view a copy of this licence, visit http:// creativecommons.org/licenses/by-nc/4.0/.

\section{REFERENCES}

1. Gilhar A, Laufer-Britva R, Keren A, Paus R. Frontiers in alopecia areata pathobiology research. J Allergy Clin Immunol. 2019;144:1478-89.

2. Safavi K. Prevalence of alopecia areata in the First National Health and Nutrition Examination Survey. Arch Dermatol. 1992;128:702.

3. Dainichi T, Kabashima K. Alopecia areata: what's new in epidemiology, pathogenesis, diagnosis, and therapeutic options? J Dermatol Sci. 2017;86:3-12.

4. Xiao FL, Yang S, Liu JB, et al. The epidemiology of childhood alopecia areata in China: a study of 226 patients. Pediatr Dermatol. 2006;23:13-8.

5. McElwee KJ, Tobin DJ, Bystryn JC, King LE Jr, Sundberg JP. Alopecia areata: an autoimmune disease? Exp Dermatol. 1999;8:371-9.

6. Wang E, McElwee KJ. Etiopathogenesis of alopecia areata: why do our patients get it? Dermatol Ther. 2011;24:337-47.

7. Leung MC, Sutton CW, Fenton DA, Tobin DJ. Trichohyalin is a potential major autoantigen in human alopecia areata. J Proteome Res. 2010;9: 5153-63. 
8. Wang J, Lu Z, Au JL. Protection against chemotherapy-induced alopecia. Pharm Res. 2006;23:2505-14.

9. Jimenez JJ, Yunis AA. Vitamin D3 and chemotherapy-induced alopecia. Nutrition. 1996;12:448-9.

10. Bikle DD. Vitamin D metabolism and function in the skin. Mol Cell Endocrinol. 2011;347:80-9.

11. Baeke F, Takiishi T, Korf H, Gysemans C, Mathieu C. Vitamin D: modulator of the immune system. Curr Opin Pharmacol. 2010;10:482-96.

12. Hewison $M$. An update on vitamin $D$ and human immunity. Clin Endocrinol (Oxf). 2012;76:315-25.

13. Arnson Y, Amital H, Shoenfeld Y. Vitamin D and autoimmunity: new aetiological and therapeutic considerations. Ann Rheum Dis. 2007;66:1137-42.

14. Holick MF. The vitamin D deficiency pandemic: approaches for diagnosis, treatment and prevention. Rev Endocr Metab Disord. 2017;18:153-65.

15. Holick MF, Binkley NC, Bischoff-Ferrari HA, et al. Evaluation, treatment, and prevention of vitamin D deficiency: an Endocrine Society clinical practice guideline. J Clin Endocrinol Metab. 2011;96: 1911-30.

16. Nowson CA, McGrath JJ, Ebeling PR, et al. Vitamin $\mathrm{D}$ and health in adults in Australia and New Zealand: a position statement. Med J Aust. 2012;196:686-7.

17. Khadilkar SS. The emerging role of vitamin D3 in women's health. J Obstet Gynaecol India. 2013;63: 147-50.

18. Tsai TY, Huang YC. Vitamin D deficiency in patients with alopecia areata: a systematic review and meta-analysis. J Am Acad Dermatol. 2018;78: 207-9.

19. Lee S, Kim BJ, Lee CH, Lee WS. Increased prevalence of vitamin D deficiency in patients with alopecia areata: a systematic review and meta-analysis. J Eur Acad Dermatol Venereol. 2018;32:1214-21.

20. Yilmaz N, Serarslan G, Gokce C. Vitamin D concentrations are decreased in patients with alopecia areata. Vitam Trace Elem. 2012;1:3.

21. Attawa E, Kandil A, Elbalaat W, Samy A. Assessment of vitamin d level in patients of alopecia areata. J Clin Investig Dermatol 2016;4.

22. Darwish N, Marzok H, Gaballah M, Abdellatif H. Serum level of vitamin D in patients with alopecia areata. Egypt J Basic Appl Sci. 2017;4:9-14.
23. El-Mongy NN, El-Nabarawy E, Hassan SA, Younis ER, Shaker O. Serum 25-hydroxy vitamin D3 level in Egyptian patients with alopecia areata. J Egypt Women's Dermatol Soc. 2013;10:37-41.

24. d'Ovidio R, Vessio M, d'Ovidio FD. Reduced level of 25-hydroxyvitamin $\mathrm{D}$ in chronic/relapsing alopecia areata. Dermatoendocrinology. 2013;5:271-3.

25. Saleh HM, Abdel Fattah NS, Hamza HT. Evaluation of serum 25-hydroxyvitamin D levels in vitiligo patients with and without autoimmune diseases. Photodermatol Photoimmunol Photomed. 2013;29:34-40.

26. Holick MF. Sunlight and vitamin D for bone health and prevention of autoimmune diseases, cancers, and cardiovascular disease. Am J Clin Nutr. 2004;80:1678S-88S.

27. Bhat YJ, Latif I, Malik R, et al. Vitamin D level in alopecia areata. Indian J Dermatol. 2017;62:407-10.

28. Aksu Cerman A, Sarikaya Solak S, Kivanc Altunay I. Vitamin D deficiency in alopecia areata. Br J Dermatol. 2014;170:1299-304.

29. Mahamid M, Abu-Elhija O, Samamra M, Mahamid A, Nseir W. Association between vitamin D levels and alopecia areata. Isr Med Assoc J. 2014;16: 367-70.

30. Abdel F, Nermeen SA, Darwish N, Yasser W. Assessment of serum 25-hydroxyvitamin D levels in patients with extensive/recalcitrant alopecia areata before and after PUVA and NB-UVB therapy. J Egypt Women's Dermatol Soc. 2015;12:19-23.

31. Bakry OA, El Farargy SM, El Shafiee MK, Soliman A. Serum vitamin D in patients with alopecia areata. Indian Dermatol Online J. 2016;7:371-7.

32. Conic RZ, Miller R, Piliang M, Bergfeld W, Atanaskova Mesinkovska N. Comorbidities in patients with alopecia areata. J Am Acad Dermatol. 2017;76: 755-7.

33. Erpolat S, Sarifakioglu E, Ayyildiz A. 25-Hydroxyvitamin D status in patients with alopecia areata. Postepy Dermatol Alergol. 2017;34:248-52.

34. Ghafoor R, Anwar MI. Vitamin D deficiency in alopecia areata. J Coll Physicians Surg Pak. 2017;27: 200-2.

35. Daroach M, Narang T, Saikia UN, Sachdeva N, Sendhil Kumaran M. Correlation of vitamin D and vitamin $\mathrm{D}$ receptor expression in patients with alopecia areata: a clinical paradigm. Int J Dermatol. 2018;57:217-22. 
36. Gade VKV, Mony A, Munisamy M, Chandrashekar L, Rajappa M. An investigation of vitamin D status in alopecia areata. Clin Exp Med. 2018;18:577-84.

37. Unal M, Gonulalan G. Serum vitamin D level is related to disease severity in pediatric alopecia areata. J Cosmet Dermatol. 2018;17:101-4.

38. Marahatta S, Agrawal S, Khan S. Study on serum vitamin $D$ in alopecia areata patients. J Nepal Health Res Counc. 2019;17:21-5.

39. Rehman F, Dogra N, Wani MA. Serum vitamin D levels and alopecia areata-a hospital based case-control study from North-India. Int J Trichol. 2019;11:49-57.

40. Siddappa H, Kumar YHK, Vivekananda N. Evaluation of association of vitamin $\mathrm{D}$ in alopecia areata: a case-control study of 100 patients in a tertiary rural hospital of Southern India. Indian Dermatol Online J. 2019;10:45-9.

41. van Etten E, Mathieu C. Immunoregulation by 1,25-dihydroxyvitamin D3: basic concepts. J Steroid Biochem Mol Biol. 2005;97:93-101.
42. Boonstra A, Barrat FJ, Crain C, Heath VL, Savelkoul HF, O'Garra A. 1alpha,25-Dihydroxyvitamin d3 has a direct effect on naive CD4(+) T cells to enhance the development of Th2 cells. J Immunol. 2001; 167:4974-80.

43. Heaney RP. Vitamin D in health and disease. Clin J Am Soc Nephrol. 2008;3:1535-41.

44. Nancy AL, Yehuda S. Prediction and prevention of autoimmune skin disorders. Arch Dermatol Res. 2009;301:57-64.

45. Zella JB, McCary LC, DeLuca HF. Oral administration of 1,25-dihydroxyvitamin D3 completely protects NOD mice from insulin-dependent diabetes mellitus. Arch Biochem Biophys. 2003;417:77-80.

46. Kim DH, Lee JW, Kim IS, et al. Successful treatment of alopecia areata with topical calcipotriol. Ann Dermatol. 2012;24:341-4.

47. Goh C, Finkel M, Christos PJ, Sinha AA. Profile of 513 patients with alopecia areata: associations of disease subtypes with atopy, autoimmune disease and positive family history. J Eur Acad Dermatol Venereol. 2006;20:1055-60. 